\title{
Optimizing Ultralow Interfacial Tension by altering Surfactant Concentration through Emulsion Test
}

\author{
M. J. A. Prince* \\ Department of Petroleum Engineering, AMET University, Chennai, Tamil Nadu - 603112, India; \\ Prince466@gmail.com
}

\begin{abstract}
Objectives: To select a specific concentration of surfactant, that could optimize Ultralow Interfacial tension between oil and Water. Formation of micro emulsion through Emulsion Test. Methodology: This work has been done through conductivity measurement of eight different surfactant concentrations to determine stable Critical Micelle Concentration (CMC). This concentration has been tested with different concentrations of electrolyte and alkali for middle layer micro emulsion. Results and Observations: Sodium Dodecyle Sulphate has been chosen for conductivity test. Through conductivity test $\mathrm{CMC}$ has been determined at 500ppm concentration. It has been tested with different concentrations of electrolyte and alkali for middle layer micro emulsion. Third layer have been appeared at $\mathrm{NaCl} 1.0 \mathrm{wt} \%$ and Alakli $0.5 \mathrm{wt} \%$. At this particular concentration IFT between Oil and Water have been reduced.
\end{abstract}

Keywords: Emulsion Test and Critical Micelle Concentration, Surfactant Concentration, EOR

\section{Introduction}

Most of the Indian fields are matured and the production has crossed its peak level during waterflooding and right now it is at declined state. Research and development programs on EOR related to Indian matured fields are required. Mostly all matured fields in India are owned by ONGC. Due to complex nature of fields, ONGC is attracting for more joint ventures but results were few ${ }^{1}$.

One of the most demanding and promising methods in EOR is the application of chemicals to extract additional oil, keeping the environmental concerns and health of the reservoirs. Though laboratory results promise high, while applying in the field, the results are not satisfactory at present. The selection of chemicals best suited in different types of reservoirs understanding each reservoir characteristics like adsorption, wettability and other factors are important factors ${ }^{2}$. The potential ability of chemical EOR, to produce additional oil is effective, as well as expensive. In last five years, the importance of chemical flooding in EOR process is proliferating because of its ability to produce more oil than any other EOR method ${ }^{3}$.

The IFT decreases sharply as surfactant concentration increases until the CMC Critical micelle concentration is reached. Beyond the CMC, little change in IFT occurs4.

\section{Methods and Mechanisms}

\subsection{Selection of Surfactant}

Interfacial Tension is the tension created at interface, where two immiscible fluids are in contact and plays a major role in oil recovery process. For sandstone reservoirs, surfactants can reduce IFT between hydrophobic and hydrophilic phases and for carbonate and tight reservoirs it alters the wettability. Critical micelle concentration (CMC) is a characteristic of surfactant, where Micelles start to form at a particular concentration Figure 1. This indicates complete separation of all phases and ultralow IFT have been achieved ${ }^{6}$. IFT will have an effect

${ }^{*}$ Author for correspondence 
on surfactant concentration Figure 2. Ultralow IFT can be achieved by formation of micro emulsions with a middle layer shown in Figure 4.
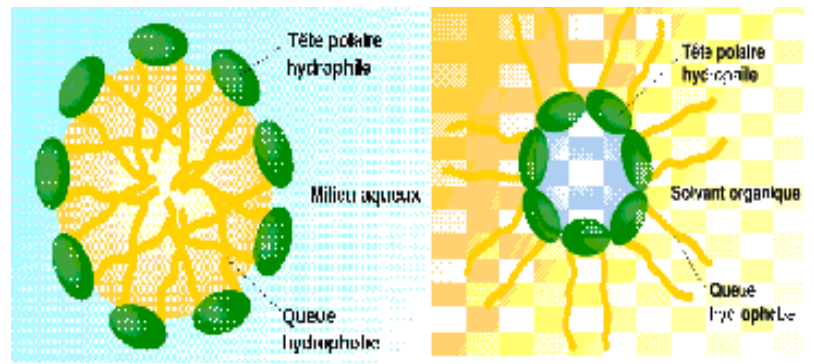

Figure 1. Micelle alignment in polar and organic phases.

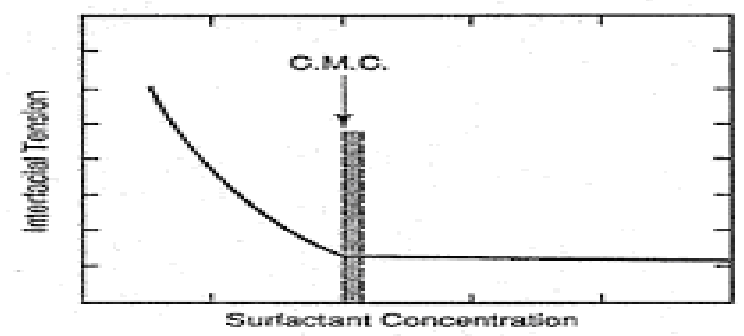

Figure 2. Surfactant concentration vs. IFT.

\subsection{Equivalent Alkane Carbon Number (EACN)}

For any given surfactant whenever IFT is measured between water and homologous series of alkanes, a profile can be obtained which resembles that in Figure 3 the lowest IFT occurs with a hydrocarbon having a particular Alkane number which is equivalent to the same Alkane number of surfactant ${ }^{7}$.

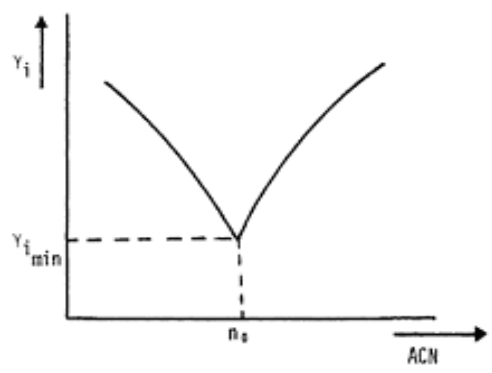

Figure 3. EACN vs. IFT.

Matching of surfactants, producing their lowest interfacial tension at specific alkane carbon number with crude oils having the same equivalent alkane carbon number (EACN). no is a function of oil phase composi- tion, aqueous phase composition, surfactant composition and concentration, cosurfactant composition and concentration, and temperature.

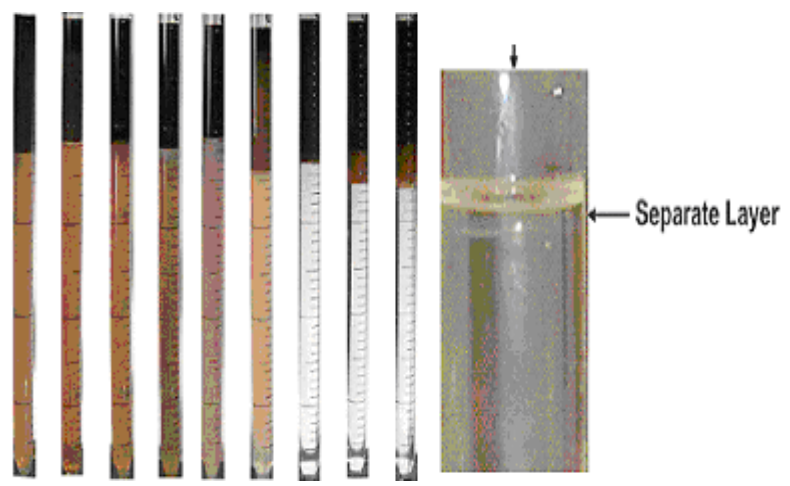

Figure 4. Emulsion tests for different concentrations of $\mathrm{NaCl}$ and $\mathrm{Na} 2 \mathrm{CO} 3$.

Crude oil behaves during measurement of IFT against aqueous phases as though they were a homogeneous hydrocarbon with a particular ACN. This carbon number is referred to as the EACN (equivalent alkane carbon no.) of the crude oil.

\section{Observation and Result}

Conductivity measurements, by varying eight surfactant concentrations have been done. Conductivities were measured each time by addition of $100 \mathrm{ppm}$ as shown in Table 1. Deviation has been observed at 500ppm shown in Figure 5. Micro emulsion, separating oil and water as individual phases have been observed at $\mathrm{NaCl} 1.0 \mathrm{wt} \%$ and Na2CO3 0.5 wt\%. With these concentrations IFT was measured by Spinning Drop Tensiometer to be 10-3 dynes/cm.

Table 1. Conductivity vs. Concentration

\begin{tabular}{|l|c|c|}
\hline Sample & $\begin{array}{c}\text { Conductivity } \\
\mathrm{mS} / \mathrm{cm}\end{array}$ & SDS ppm \\
\hline 1 & 10 & 100 \\
\hline 2 & 17 & 200 \\
\hline 3 & 21 & 300 \\
\hline 4 & 26 & 400 \\
\hline 5 & 30 & 500 \\
\hline 6 & 32 & 600 \\
\hline \hline 7 & 32 & 700 \\
\hline 8 & 33 & 800 \\
\hline
\end{tabular}




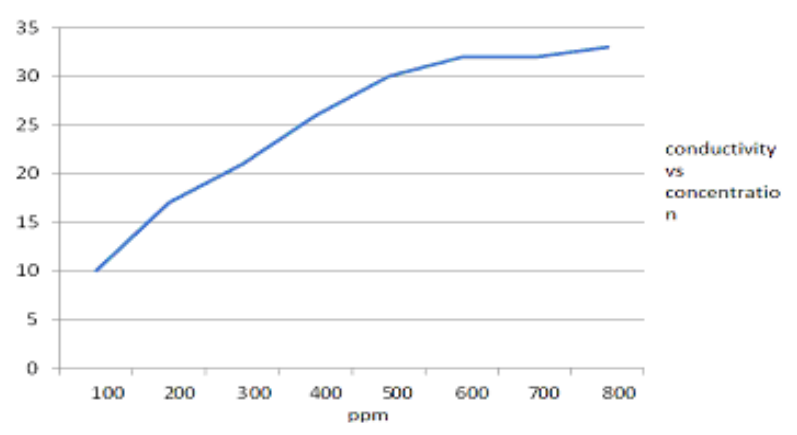

Figure 5. Plot of CMC determination.

Nine combinations of emulsions with 500 ppm SDS in $25 \mathrm{ml}$ test tubes have been tested with Oil, brine and alkali as shown in Table 2 .

Table 2. SDS Emulsion with Brine and Alkali

\begin{tabular}{|l|l|l|l|}
\hline $\begin{array}{l}\text { SDS ppm } \\
\text { in } 12.5 \mathrm{ml}\end{array}$ & $\begin{array}{l}\mathrm{NaCl} \\
\mathbf{w t} \%\end{array}$ & $\begin{array}{l}\mathrm{Na}_{2} \mathrm{CO}_{3} \\
\mathbf{w t} \%\end{array}$ & $\begin{array}{l}\text { Appearance in } \\
\text { Layers }\end{array}$ \\
\hline 500 & 0.0 & 0.0 & 1 phase \\
\hline 500 & 0.5 & 0.0 & 2 phases \\
\hline 500 & 1.0 & 0.0 & 2 phases \\
\hline 500 & 0.0 & 0.5 & 2 phases \\
\hline 500 & 0.0 & 1.0 & 2 phases \\
\hline 500 & 0.5 & 0.5 & 2 phases \\
\hline 500 & 1.0 & 0.5 & 3 microemulsion \\
\hline 500 & 0.5 & 1.0 & 2 phases \\
\hline 500 & 0.5 & 1.0 & 2 phases \\
\hline
\end{tabular}

Middle layer have been observed at $1.0 \mathrm{wt} \%$ brine and $0.5 \mathrm{wt} \%$ alkali. The appearance of third middle layer is due to microemulsion formation. At $500 \mathrm{ppm}$, SDS formed micelles with aqueous and Organic phases by reducing
IFT to optimum level. This separates Oil and water into individual phases and forms three layers.

\section{Conclusions}

Oil recovery can be optimized by Reducing IFT. Ultralow IFT can be achieved by selecting proper surfactant concentration. Surfactants have been shown to be effective in recovering unswept oil by reducing residual oil saturation (micellar or surfactant polymer flooding (SP), alkaline/ surfactant/polymer (ASP)). Surfactants are costly compared to other chemical used in chemical EOR process. Cost effective surfactants has to be synthesized. Research must be done on surfactant adsorption to different reservoir surfaces.

\section{References}

1. Mustafa S, Dilara B, Nargis K, Naeem A, Shahida P. Surface properties of the mixed oxides of iron and silica. Colloids Surf A. 2002; 205(3):273-82.

2. Schramm LL. Surfactants: fundamentals and applications in the petroleum industry. Cambridge, United Kingdom: Cambridge University Press; 2000.

3. Kokal S, Al-Kaabi A. EOR challenges and opportunities. Tech Innovat. London, United Kingdom: World Petroleum Council; 2010. p. 64-9.

4. Rosen MJ. Surfactants and Interfacial Phenomena. 2nd ed. NY: John Wiley and Sons; 1989. p. 5-80.

5. Salager JL. Surfactants types and uses. 25-40.

6. Ottewill RH. Introduction, Surfactant. Tadros TF, editor. San Fransisco: Economic Press; 1984. p. 1-18.

7. Cayias JL, Schechter RS, Wade WH. Modelling crude oils for low interfacial tension. SPEJ. 1976 Dec; 16(6):351-7. 